\title{
Claude Sumner's “Oromo Wisdom Literature:" An Attempt at Understanding their Philosophical Content
}

\author{
Bekele Gutema*
}

\begin{abstract}
In his lifelong work at the Department of Philosophy of Addis Ababa University, Sumner initially worked on the written sources of Ethiopian philosophy. It is after the production of multiple volumes on the written sources that he turned to the oral sources. The major ones are contained in three volumes titled, "Oromo Wisdom Literature." By developing an approach that looked at philosophy in the broader and strict senses Sumner studied the different oral sources of Oromo philosophy. His approach to philosophy was that, while writing is a very important aspect of doing philosophy, this does not, however, mean that oral sources cannot have philosophical content. This is what has been demonstrated by H. Odera Oruka's sage philosophy. Sumner used proverbs, songs, folktales, riddles and similar oral materials to distill philosophical content out of some of them. The paper will try to show how oral sources could be considered as philosophy in the broad sense, while there is also a possibility that such material could be changed into philosophy in the strict sense by philosophers. By briefly analyzing Sumner's position on this, I will try to show the significance of oral wisdom/literature not only for philosophy but also other types of intellectual activity.
\end{abstract}

Keywords: Wisdom Literature, Philosophy, Sagacity, Fictitious Narratives DOI: https://dx.doi.org/10.4314/ejossah.v15i1.4

*Professor, Department of Philosophy, Addis Ababa University email: bekele_gutema@yahoo.com, Tel: +251911500871, P.O. Box 1176/ Addis Ababa.

This work is licensed to the publisher under the Creative Commons Attribution-NonCommercialNoDerivs License. 


\section{Introduction}

Sumner's contribution to scholarship in Ethiopia is immense. As he often used to say, he fell in love with Ethiopia as soon as he landed in Addis Ababa. After working for some years, he started to express himself as "Canadian by birth and Ethiopian by choice." He tried to substantiate the statement that he is Ethiopian by choice through his dedicated services to Ethiopia in his teachings and research that lasted nearly half a century.

He educated many generations of Ethiopians. His contribution in research to Ethiopian scholarship is considerable. He began to use the expression Ethiopian philosophy, when many were questioning the existence of African philosophy. The fruits of the debate in African philosophy are well known. He found a favorable situation in Ethiopia since he was able to come across written sources with philosophical content. Emboldened by what he had done regarding written sources and learning from the debates in African philosophy and the focus on oral sources among scholars including O. Oruka's sage philosophy and the evolving interest in oral literature he turned to what he termed Oromo wisdom literature.

This was an activity justified by what was happening in the areas of oral literature and more importantly by the content of what could be found in oral wisdom as attested to by other scholars. It was in this way that the analysis of collected proverbs, songs and folktales took place.

In this short article an attempt will be made to show the importance of oral wisdom in terms of its content and also the utility it could have for intercultural philosophical dialogue. Just like O. Oruka was able to extract useful philosophical ideas from the Luo sages in Kenya, Sumner was also able to extract wisdom from proverbs, folktales and fictitious narratives in general. I have attempted to show what he has done and its wider implications for philosophical research.

\section{Oral Wisdom as a Source of Philosophy: Nature and Meaning of Philosophy}

In his nearly half a century of teaching and research at Adds Ababa University, Sumner initially worked on the written sources of Ethiopian philosophy. His works on written Ethiopian philosophy are contained in five volumes and numerous articles. The majority of them are based on sources translated from either Arabic or Greek sources into Geez. A question that arises here is that, if they are translations from foreign sources, how can we call them Ethiopian? This is a point that Sumner thought about in his works. Without denying their being translations Sumner argued that they have not only been translated, but also adapted to the Ethiopian 
context. Works like "The Book of the Wise Philosophers," "Skendes," and "The Fisalgwos" are the ones that have been translated and also made in such a way that they are made to fit into the Ethiopian context.

One of the major works from the written sources of Ethiopian philosophy is, "The Treatise of Zara Yacob and of Walda Heywat." His work on the two deals with the texts composed by Zara Yacob and Walda Heywat. After presenting the text, Sumner analyzed the contents of the works of Zara Yacob and Walda Heywat. He then addressed the issue of authorship trying to debunk the assertion by some that the work was not that of an Ethiopian thinker, but of an Italian missionary. Using different sources including those that are found in the libraries in Europe he tried to show that the works are that of two Ethiopian thinkers/philosophers (Sumner, 1976). Sumner's work took a long period of time. He eventually turned to the oral sources of philosophy, in this case what he termed "Oromo Wisdom Literature."

He justified his study of oral sources based on the condition of the Oromo. These refer to geography, size of the Oromo population, the Oromo culture and the role of oral sources in philosophy and other intellectual activities. More importantly he wanted to do this drawing on the experiences of other scholars who studied oral literature.

A people expresses its world outlook, its values and norms, its moral codes, its conception of the ideal society and the like through its fictitious narratives/philosophy. This philosophy could be written or oral. Of course there is a difference when you do philosophy, for an academic exercise and when you do it as the expression of life. The ones who do philosophy for an academic purpose practice it for the purpose of rigorously expressing "a philosophical truth." But those who do philosophy as the expression of their lives live their philosophy as the guiding principle of their lives.

These are some of the ideas behind Sumner's approach to oral sources of the Oromo in order to discover Oromo philosophy which is contained in the different forms of oral literature. The sources that Sumner used are mainly proverbs, songs, folktales, riddles, poems, and myths. It is with the assumption that a lot of important ideas can be gleaned from those sources, that he delved into the study of oral literature.

Sumner was very much aware of the debates taking place regarding African philosophy during the 1970s and 1980s. Among other things the debate on ethnophilosophy generated by the publication of Temples' book titled, "Bantu Philosophy" (1945) was important. He was aware of Odera Oruka's and the other professional philosophers' works on ethnophilosophy. He believed that a 
philosophy of a people that is expressed in different forms can be discovered from the oral literature of a people like that of the Oromo.

In order to do that he had to introduce the notion of philosophy in the strict and broad senses. Such a division, in his opinion, is not meant to show that the one type of philosophy is more important than the other. His distinction between the two is not meant to favor one way of doing philosophy over against another, since he thought that despite differences in context, content and time, philosophy, however, has to be taken as philosophy. Hence, he used this division to show on the one hand that philosophy has many sources and faces; and that its birth place also should not be confined to a specific geographical region or a certain group of people. Moreover, he wanted to underline the importance of such philosophy when viewed from the perspective of theoretical issues and more importantly that of practical problems. He wrote: Philosophy may be taken in a broad sense and in a narrow and more precise way...philosophy in strict sense refers methodologically, to a reflective, systematic, deep and thorough way of thinking, and historically, to a vast and rich display of subjects which have engaged the attention of different thinkers, at different times... philosophy attempts to grasp the entire universe in a small number of principles (Sumner, 1995: p. 22).

Philosophy in the strict sense for Sumner refers to the kind of academic philosophy practiced in universities and similar institutions. It is preoccupied with the purpose of seeking the truth whether this is in the realm of practical philosophy or theoretical philosophy. Such an understanding of philosophy has been the dominant understanding of philosophy. Sumner questions the wisdom of restricting philosophy to this kind of philosophy alone. He thought that such an understanding of philosophy is biased to other ways of relating to reality and life, in favour of written and logocentric way of doing philosophy. The question therefore, for him, is that the philosophy/wisdom of human kind must not be limited to the ideas of a few philosophers who have left their ideas in writing and who have been grappling with answering metaphysical, epistemological and axiological questions. The introduction of the idea of philosophy in the broad sense is important, according to Sumner, to address this issue. He described philosophy 
in the broad sense as follows: "...philosophy may also be taken in a wider sense as "wisdom. Wisdom is not the same as knowledge; it does involve knowledge, but it also includes the ability, the inclination and the steady purpose of putting knowledge to good use" (Sumner, 1995: p. 22).

In this case Sumner refers to wisdom that guided people through generations. The point of departure for wisdom should be a specific event, experience, or problem for which solution is sought. The ways in which this wisdom is expressed varies. Some come to us in the form of proverbs; others in the form of folktales, riddles, songs, poems and so on. The underlying point of this approach is that humans relate to reality, life and other things in a thoughtful way. Based on their own experiences and that of the previous generations they use a kind of reasoning that shows the way in which life should be lived peacefully, harmoniously and in ways that the continuity of generations are guaranteed. This means that they have thoughts that can be considered as philosophy in the broad sense. It is this philosophy that defines their way of life, their norms of right and wrong, their understandings of justice and the good life. It is with this understanding that Sumner studied the collection of Oromo proverbs and other oral sources like poems, riddles, songs and even myths. If I may focus on the first volume, which deals with proverbs, among other things, he tried to show the different functions of proverbs. He identifies five different functions: namely, 1) cognitive, 2) expressive, 3) normative and educative, 4) discursive and 5) cultural functions.

Cognitively, proverbs give form to reality. Based on some experience a proverb uttered renders an understanding of a situation in which it was uttered. Definitely it is uttered in a context. It will give you the picture of a situation in which it was uttered and enables one to enlighten a situation of a similar nature (Sumner, 2001, p. 38).

Cognition leads to expression. Depending on the situation and nature of the proverb one expresses either approvingly or disapprovingly what one was able to understand through the proverb (Sumner, 2001, p. 38).

Proverbs have normative and educative functions. Apart from rendering possible understanding, proverbs also shape behavior. They set norms and standards in accordance with which members of a community distinguish between good and bad, right and wrong and so on. Proverbs train individuals and society on norms that need to be followed in a given community (Sumner, 2001, p. 39).

A proverb happens in a discourse. "In a conversation, proverbs represent the highest point... Proverbs are the summits of the arc of thought" (Sumner, 2001, p. 39). 
Finally, of course, proverbs have a cultural function. "The proverb is a dialogue with the truth recognized in the group in which the participants in the dialogue and the public participate" (Sumner, 2001, p. 39).

What Sumner did in his approach to wisdom literature, particularly proverbs, songs, folktales, riddles, etc. is to look into the narratives of the people as it comes down to us in the forms mentioned. Such material is important to see the life-world of the people. This is more so when looked at from a philosophical perspective. The components of oral literature are not produced in a vacuum. They are produced in a context of time and space. They are not mere fabrications without a purpose. They are material that are necessitated by the real situation of life and have significance in similar situations. We can refer to a wide array of oral literature including myths that may be considered not so important at face value, but a close consideration of each one of them can tell us why, how and for what purpose they might have been produced. Regarding Myths V. Y. Mudimbe said:

If one can look into an African myth or ritual and recognize in it, as in the case of the Dogon myth, a powerful and amazing organization of classifications, filiations, and their transformations and representations, it would be wrong to limit the meaning of the myth to this function. A careful student always goes beyond the formal systems and unveils other symbolic networks, of which the members of the community might be absolutely unaware. Myths are autonomous bodies (1988, p. 157).

Sumner's works on oral literature can be considered in this sense. Others who studied oral literature and other iconic traditions attest to the point that stories, folktales, proverbs, songs, paintings, sculpture and the like express the world views of the people, their struggle for a better life, disappointments, hopes and aspirations. One of Africa's very well-known writers, Wole Soyinka is a person who dealt with the issues of iconic traditions and fictitious narratives. According to him and others, fictitious narratives, folktales, and other forms of literary expression, both written and oral provide a window into profound metaphysical and moral values of a people. They are the icons of a people and can be considered as the storehouse of their knowledge that has different manifestations. What we find in them is a sagacity that could be of considerable value even when seen interculturally (Soyinka 1976, p. 1985). 
Philosophers, writers and other scholars who worked on oral societies attest to the point that there is considerable wisdom/sagacity expressed through different oral material like proverbs, poems, songs, narratives accruing from palavers, and other icons. They show how a given community understands itself. Based on its own experiences it evaluates its own values, sets different standards for different norms and actions. Some of this material can be considered as a profound critique of the social, economic, political and cultural practices of the given community or the status quo in general. It can be seen as how a community and particularly its sages pose as critics of the status quo, showing in many cases dissatisfaction with the status quo and also the aspiration for a better future. How to realize such a goal and an aspiration can also be expressed in different forms in these kinds of narratives.

Indicating the importance and philosophical value of a proverb, Sumner writes, citing the following proverb, "hawks fight in the sky for a piece of meat on the ground"

...a person who in a given situation says something concerning it...expresses a logical truth of a cognitive order, like the man mentioned above who intervenes during a quarrel. But he also expresses a vital truth; beyond the purely cognitive aspect, there is the involvement of the sender [the man who utters the proverb]. The proverb translates his profound sentiment, his affective position approving or disapproving the experienced situation. "Excuse me" the man tells the wranglers, "but your quarrel cannot settle anything" (Sumner, 2001, p. 25).

A close reading of the collection of the proverbs that he published shows the content of the proverbs. It is possible to understand that many of the proverbs perform one or the other of the five functions mentioned above.

The role of critique in philosophy and its pervasive applicability in many domains of life is also a point that needs to be mentioned. Critique makes philosophy what it is. The understanding of philosophy as a rational and critical intellectual exercise and that nearly all important philosophers used critique to unravel their philosophical concepts is a testimony to this. In the kind of wisdom that we access through oral literature also critique plays a role. In folktales and the different forms of fictitious narratives critique is pervasive. Fictitious narratives are about some aspect of human life. They are things through which people understand their situation, evaluate their deeds, and criticize the adverse phenomena that they 
encounter in life. They relate to different practices and norms approvingly or disapprovingly. Proverbs and maxims, for example, have exhortatory statements containing dos and don'ts. In daily life many people have a tradition and habit of carrying out critique of such phenomena. It is these phenomena that we see when we deal with oral literature. It is to be understood that critique of this nature constitute an important component of wisdom literature. It is logical to assume that where there is domination/exploitation, of some sort, for example, there would be critique. It is impossible to find an aspect of social life that can be insulated from critique. The explorations that we make into fictitious narratives show the role that critique has in social life. Richard Bell says, "Africa's oral narratives actively and critically involve their participants in a dialogue in which many questions are posed but for which not all answers are directly supplied. To listen to these narratives even if once or more removed from them shows the critical level of their operation and reveals their significance for philosophy" (2002. p. 110-111, emphasis mine).

R. Bell who believed that there are lots of valuable sagacious materials in oral and fictitious narratives describes Soyinka's position as follows:

Soyinka gives special focus to the moral and metaphysical concerns of African people as expressed through their "fictitious narratives". An African philosophy in its narrative aspect, should "translate the inherent or stated viable values of a social situation into a contemporary or future outlook. The "inherent or stated viable values" are those embedded in one's particular narrative situation, and the continuous translation of these values is, for Soyinka, a revolutionary activity (Bell, 2002, p. 119).

While there are numerous works on proverbs and other oral sources, they were mostly considered from the point of view of literature. What is interesting about Sumner's works regarding wisdom literature could be extended to philosophy as well. Such work has already been done by Odera Oruka. The difference between the two is that Oruka identified living sages and tried to get their ideas, particularly asking them to answer philosophical questions. Sumner on the other hand consulted the oral sources left behind by sages and other members of the community. The material that they left behind is to be found in proverbs, poems, myths and other forms of fictitious narratives. He was convinced that proverbs and other oral material stand as the storehouse of the accumulated experience, knowledge and philosophy of the people. 
This is a trend that has been adopted by other scholars, like Richard Bell who focused on the study of oral sources of philosophy. For Bell, oral sources, iconic traditions, and fictitious narratives found in the kind of material that Sumner used are important sources of philosophical knowledge and they play important roles in two ways. First of all it is a source for understanding the people concerned; it is a philosophy of the concerned people. Secondly, it is something that is necessary from the point of engaging in dialogue with other [Western, Asian, Latin American) philosophical traditions. It is an important material to advance intercultural dialogue.

The following statements of Bell actually shed light on the intent and purpose of Sumner's works. According to Bell,

Among the central kinds of narrative texts in Africa and of particular importance to philosophy are those to be found in its oral traditions and in its recent literature and art. Furthermore the development of civil society in particular in African nations needs to be tied as much to patterns found in local council structures and the rational dialogue of village palavers as to either one party or multiparty democracies or to Western social engineers. To call forward traditions of orality alongside art and literature and explore how these contribute to African philosophy... they are essential to grasping the present African reality, especially if the grasp is from outside the African continent (2002, p. 109-110).

Today we all know that indigenous knowledge is very important not only from the perspective of heritage but also its utility both internally and externally. Scholars put emphasis on indigenous knowledge in relation to the environment, production, education, upbringing of children and so on. It is vis-à-vis its immediate utility that such knowledge is being promoted. Sumner turned to oral wisdom literature without using the expression indigenous knowledge, but the act as we see it is an attempt to look for an indigenous source of philosophy. It has something that has a useful purpose. It inspired and could still inspire many to look for indigenous sources of philosophy that could be approached from the two perspectives just mentioned.

What Sumner did in this regard can also be seen as a kind of a clarion call to return to the source in order to know a people and also see the utility of oral wisdom. It can comfortably be related to what Soyinka calls "the revaluation of 
traditional values". Such an approach calls for the necessity of evaluating and appropriating, particularly what many call traditional/indigenous knowledge. It is the revaluation of such knowledge and values that will enable us to understand the society that owns such values.

\section{Oral Wisdom as a Source of Philosophy: A Critical Appraisal}

Sumner embarked on a new path when he turned to oral wisdom as a source of philosophy. In a situation where philosophy is predominantly understood as written, logocentric and adversarial, it is not easy to be convinced that wisdom can also be found in oral sources and starting to study it. His attempt to make a distinction between philosophy pursued for the sake of knowledge and philosophy as wisdom that has impact in life where its owners live their philosophy is important. The act of trying to use wisdom "for the steady purpose of putting it to good use" reminds philosophers of an important way in which they should approach philosophy. Further, by undertaking such a study he has shown philosophers, young and old alike, a new way in which philosophy needs to be approached. Such oral wisdom could be a useful area of philosophical research. It could enable the understanding of communities approached in this way. Moreover, it could also supply useful philosophical knowledge that could enrich philosophical dialogue.

The time when Sumner turned to oral wisdom literature was a time when the debate on African philosophy was coming to a close and particularly when philosophers like Hountondji who initially underlined the imperative of writing for philosophy and the role of the individual philosopher were reconsidering their position. Referring to this position G. Presbey said,

Hountondji admitted that his earlier rejection of collective thought was excessive. He explained that collective culture must be taken seriously and that individuality is fashioned from a basic personality which has rootedness. While he agrees that individual thought should be seen in cultural context, he notes that it should not be stuck there. Roots should not be a prison house (Presbey, 2007, p. 145).

As can be seen from Presbey's statements, there emerged a stance that oral sources could not only be philosophy, but a source of philosophy. Sumner's three volumes titled, "Oromo Wisdom Literature" focus on proverbs (Vol. I), Songs (Vol. II), and folktales (Vol. III.) He approached wisdom literature through 
elements of oral literature that are limited. Oral literature is vast and can be considered through various categories of oral sources. It is a rich source that can be seen as an entry point into the life world of a people. Societies that did not have the culture of writing have world views, values and other forms of knowledge around which they organize their lives. When one closely listens to them and tries to understand their fictitious narratives, listens to their songs, and analyzes their mythical expressions, one understands the kind of knowledge and values around which their lives are built.

It is known that historians built the idea of the history of African peoples (societies) based on oral sources. This helped debunking the idea that Africans have no history. Philosophers and writers have done and are doing the same thing regarding philosophy, artistic creation, education and the like. In fact the denial of history to a people and rejection of their ways of knowing has started to be taken as epistemicide. The return to the source through oral sources is one way of countering this tendency to kill and bury indigenous knowledge.

The point regarding philosophy is important. Philosophical questions have been questions that human beings could not avoid. Philosophical questions relate to the very survival of humans. Philosophical questions have been and still are questions through which humans find their place in the world, define themselves and establish the norms and values around which life is organized. This probably is the same for many human communities. Societies which have their own openly acknowledged philosophers see these people continuously engaging in discussions on important issues of both theoretical and practical concern. While that is the task of philosophers whose job is to think and philosophize, it is also possible that there are other philosophical ideas espoused by members of communities. We can think of how the philosophies of known persons like Socrates, Plato, etc. have an impact on their community/society. But at the same time it does not necessarily mean that these are the only philosophical ideas in that society or that the given society uses. We can assume that there are also other philosophical ideas in the community which are important to the community and which give meaning to the life, wellbeing and flourishing of the community, although it may not be known equally with the philosophy practiced by the likes of Socrates, Plato, Aquinas, etc.

We can extend this to societies that did not have and still do not have the culture of writing. We can discover an array of ideas in every community which play the role of organizing philosophical principles emanating from different oral sources. We can also think of persons in such communities that are leaders in being the originators or custodians of ideas that are vital for their communities' well-being and flourishing. We can call such persons following H. O. Oruka, 
sages. They play a multitude of roles in organizing the life of their community by maintaining values and norms and also generating new ideas that are necessary at the particular time in which they live.

Sumner and others that turned to oral sources to understand the philosophy, history, values, norms and education systems of a community do it with such an assumption. No society is without history; no society also is without education, values and norms. Many societies have philosophies that are pivotal for the way they organize their lives. It is this conviction that enabled Sumner and others to go into oral sources.

On the other hand, the attempt to understand the philosophy, culture and values of a community can be understood as returning to the source in the sense that A. Cabral understood it. Returning to the source is important both from the perspective of understanding and action. The question of returning to the source or of a cultural renaissance entails the act of looking for those sources that are important in many respects, namely, philosophy, moral values, relations between humans and the environment and so on.

What have been sketched above gives us the reasons why it is important to study the oral wisdom of a people that may exist in different forms like folktales, music (songs), proverbs, and other forms of oral expression. The manner in which communities handle their daily activities and also treat issues of communal concern like conflict resolution, community engagement in matters that are important to the community, the way decisions are made on important matters can be understood from the different oral sources.

The culture of sitting under the shade of a tree and solving problems, resolving conflicts, planning future activities are common to many communities. The Oromo have the practice known as "muka jalaa" meaning literally the practice of sitting under the shade of a tree and talk on issues. There are, indeed, no issues that cannot be handled in this way. It is an activity that is practiced all over Africa and its role in communities is quite vital. What $\mathrm{R}$. Bell said regarding village palavers in Southern Africa points to the wide-spread culture across Africa and its practical utility. That is why having recourse to such practices is important to understand the communities. Bell wrote:

The village palaver or council model in many parts of Africa is a model of free discourse for the purpose of making good judgments and for doing justice for individuals and the community. These narrative situations force dialogue and give rise to human reflection, and they are far from uncritical. Each 
dialogical situation has earmarks of the Socratic enterprise; each is formative of values characteristic of that community; each reflects the existential texture of human life; each dialectically serves to move the community from injustice to justice, from wrong to right, from brokenness to wholeness, from ignorance to truth (Bell, 2002, p. 113).

You discover the knowledge produced in this way by returning to the source. These are forms of oral expression and can be taken as aspects of the philosophy of a people. Folktales, music and other forms of fictitious narratives express, in a reflective way, aspects of the African reality. They constitute important elements of African reflective philosophical expression. Here, there is no assumption that all of them have philosophical content. But there are aspects of these practices and material that are philosophical and necessary to understand the given community, that is the author of the oral literature. Sumner's attempts to study oral wisdom literature can be understood in this sense. Again as Bell says:

What is expressed in the art of a culture, in its iconic tradition, is not accidental. Nor is it simply the spontaneous expression of emotions and feelings; it is, rather, the conscious creation of considered and often wise reflections of a people on its age, and as such deserves to be taken seriously as part of the narrative portrait of the peoples' most important concerns (Bell, 2002, p. 113).

It is important to note that anyone of the materials that can be categorized as oral wisdom literature has some specific point of departure. Proverbs come into being to enlighten a concrete situation. Songs and music in general reflect an existing situation, aspiration and concern. They are, in many cases, well thought out, reflective, critical and are meant to have impact on social, political, cultural and individual matters. The same holds true for folktales, riddles and other forms of fictitious narratives.

Oral sources are important particularly for societies that did not have a culture of writing. It is also important to evaluate the elements of culture that could be useful to humanity. It is by turning to oral sources that African historians were able to refute the assumption by Eurocentric historians that Africa has no history. It is a paradox of history that the Africa of the Pharaohs, the Africa of Aksum, Timbuktu, Songhai, Zimbabwe, Meroe, etc. was characterized as having no history 
by thinkers of the Enlightenment and modernity. It is important to note that civilizations like that of Aksum had written scripts. Zara Yacob of Aksum wrote his Treatise in Geez long before Hegel was born. In addition to oral sources there are other forms of expression found in art, sculpture and the like which are important to give meaning to the life of the community that produces them. Hence, oral sources have been useful not only in terms of excavating the sources of African history, but also its philosophy, its mechanisms of political decision making, its social and political philosophy and its moral values. This could be an endeavor that could take us a long way in enumerating the benefits and utility of oral sources. Sumner was justifiably motivated to look into Oromo wisdom literature in order to understand the wisdom and philosophy of the Oromo people. In fact scholars like Asmarom Legesse long before Sumner have been able to diagnose the anatomy of the Gadaa system which is considered to be an elaborate democratic social and political system. The attempt to focus only on written sources, whether this is in history, philosophy or other areas of knowledge hinders us from delving into a rich source of knowledge in many respects. It should be a call for African scholars to look into the rich African oral sources not only to understand Africa and what was there before an encounter between Africa and Europe was made, but also to chart a new path for Africa based on its knowledge, experience and values of its past.

\section{Conclusion}

In turning to wisdom literature Sumner took up a source of philosophy that could enrich philosophy. By approaching philosophy from the perspective of "philosophy in the strict and broad senses" he made the way open for sources of philosophy that had been marginalized for reasons that have nothing to do with philosophy. He could look up to O. Oruka's sage philosophy for inspiration. He, however, was able to expand the source of philosophy in such a way that lots of oral wisdom that could be useful from the point of view of morality and ethics, environment and education, politics and other matters could be addressed.

Turning to oral wisdom addresses another important point, that African philosophy is a late comer to the philosophic scene. Sumner shows that African philosophy may be a late comer only if philosophy is taken in its Western logocentric sense. However, there are no justifiable philosophical reasons to limit philosophy to its Western sense. The Western way of doing philosophy is just one way of doing philosophy. Particularly, when philosophy is taken in its classical or etymological sense as love of wisdom, it is something that is found in many cultures. That was what Sumner was able to demonstrate. 
Oromo wisdom literature is an important contribution to Ethiopian/African philosophy. Some of the points about Oromo culture that have been found by anthropologists and other scholars have been extended to the realm of philosophy as well. This work has further implications for other oral cultures. There is no doubt that there is similar useful wisdom in the oral cultures of many Ethiopian/African communities. In fact even for those with written cultures, there is no doubt that useful knowledge in many respects can be discovered in their sayings, proverbs, folktales and other forms of fictitious narratives. Students of African philosophy, by involving in research into oral wisdom either by following O. Oruka's method or Sumner's method or some other available method, can significantly broaden the horizon of African philosophy. This would in turn increase the knowledge that African philosophy can bring to the forum of intercultural philosophical dialogue/polylogue. 


\section{References}

Bell, R., H. (2002). Understanding African philosophy: A cross-cultural approach to classical and contemporary issues. New York and London: Routledge.

Cabral, A. (1973). Return to the source: Selected speeches by A. Cabral, edited by African information service. New York and London: Monthly Review Press.

Legesse, A. (1973). Gadaa: Three approaches to the study of Africa Society. New York: Free Press, Macmillan.

Mudimbe, V. Y. (1988). The Invention of Africa: Gnosis, philosophy, and the order of knowledge. Bloomington and Indianapolis: Indiana University Press.

Oruka, H. O. (1990). Sage philosophy, indigenous thinkers and modern debate on African philosophy. Leiden: E. J. Brill.

Presbey, M. Gail. (2007). Sage philosophy: Criteria that distinguish it from Ethnophilosophy and make it a Unique Approach within African Philosophy. Philosophia Africana, 10(2), 127- 160.

Soyinka, W. (1976). Myth, literature and the African world. Cambridge: Cambridge University Press.

Soyinka, W. (1976). Icons for self-retrieval: The African experience: A Lecture given at Oberlin College, 14 November 1985. Oberlin, Ohio.

Sumner, Claude. (1976). Ethiopian philosophy volume II, the treatise of Zara Yacob and of Walda Heywat: Text and authorship. Addis Ababa: Commercial Printing Press.

Sumner, Claude. (1995). Oromo wisdom literature volume I.: Proverbs, collection and analysis. Addis Ababa: Gudina Tumsa Foundation.

Sumner, Claude. (1997). Oromo wisdom literature volume II.: Songs, collection and analysis. Addis Ababa: Gudina Tumsa Foundation.

Sumner, Claude. (1996). Orormo wisdom literature volume III.: Folktales, collection and analysis. Addis Ababa: Gudina Tumsa Foundation.

Sumner, Claude. (2001). The proverb and oral society, in Teodros Kiros (ed.), Explorations in African political thought: Identity, community, ethics (pp. 21-45). New York \& London: Routledge.

Temples, P. (1960). Bantu philosophy. Paris: Presence Africaine. 